\title{
Academics' social positioning towards the restructured management system in Finnish universities
}

\author{
Katriina Tapanila ${ }^{\text {a* }}$
}

Faculty of Education, University of Tampere, Tampere, Finland

\section{Päivi Siivonen ${ }^{\mathrm{b}}$}

School of Educational Sciences and Psychology, University of Eastern Finland, Joensuu, Finland

Karin Filander ${ }^{\mathrm{c}}$

Faculty of Education, University of Tampere, Tampere, Finland

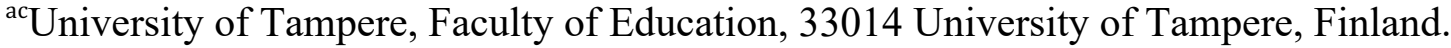 \\ aTapanila.Katriina.A@student.uta.fi, +358 05339 1252; 'Karin.Filander@uta.fi,+358 \\ 50318 1270; ' University of Eastern Finland, School of Educational Sciences and \\ Psychology, Joensuu Campus, P.O. Box 111, FI-80101 Joensuu, Finland, \\ Paivi.Siivonen@uef.fi, +358 294453388.
}




\section{Academics' social positioning towards the restructured management system in Finnish universities}

The invasion of managerialism in universities has changed the prerequisites for academic work. Decision making and control over academic work based on the expertise of academics have declined; in turn, managers have gained more decision-making power. Our study's target group comprises academics representing educational sciences in two Finnish universities, where large managerialist reforms have been carried out. We explore how the academics positioned themselves towards the new management system based on managerialism. In the analysis of our qualitative work welfare survey data, we applied a narrative-discursive approach. The positionings traced in the analysis ranged from resistance to managerialism to desire for strong management. The new management system was regarded as problematic because it was perceived as neglecting traditional academic ideals. We conclude that increased managerial control, accompanied by many administrative duties, may disturb the basic work of academics and therefore decrease the quality of research and teaching in universities.

Keywords: managerialism; professionalism; academics; university reforms; social positioning; narrative-discursive analysis

\section{Introduction}

The present-day challenge for universities is to deliver outstanding economic, social and cultural benefits and innovations to secure a nation's competitive edge. To respond to such governmental pressures, universities in Europe, including Finland and other Nordic countries, have reformed managerial structures (Degn 2016). The driving force for these reforms has been new public management (NPM), a global trend aiming at improving public-sector performance (De Vries and Nemec 2013). The NPM principles include enhanced competition, management practices drawn from the private sector, and accountability (Chandler, Barry and Clarke 2002; Deem and Brehony 2005; Huang, 
Pang and Yu 2016). NPM promotes managerialism; in the university context, it means supporting managers' capability to control and regulate academic work and shifting the authority from the academic community to managers (Gordon and Whitchurch 2010; Carvalho and Videira 2017; Shepherd 2017). Managerialism is manifested by managerialist practices, such as rules, measurements, evaluations, as well as control exercised by managers and manager-centred decision-making systems framing the daily work in universities. In this article we explore how the management system based on managerialism was perceived by academics in two Finnish universities and how they positioned themselves towards the new system.

The Finnish higher education (HE) system is based on the Nordic welfare state model, emphasising education as a public good, free and equally available for all (Välimaa 2012; Nokkala and Bladh 2014; Ylijoki 2014). However, over the past decades, university reforms based on NPM have been carried out in Finland, as well as other Nordic countries (Nokkala and Bladh 2014). In Finland, NPM-driven university reforms, along with the transition towards managerialism in HE, culminated in the New Universities Act in 2009, where universities were granted stronger financial and administrative independence in relation to the state. The reform's purposes were to facilitate universities' operations in an international environment, allocate resources to top-level research and ensure the quality and effectiveness of research and teaching (Finnish Ministry of Education and Culture 2017).

The New Universities Act in Finland reformed the universities' management system by strengthening the power of boards, rectors and deans. It also increased the resemblance between universities and businesses. University staff is no longer employed by the government; in the new system, universities follow their own staffing policies (Aarrevaara, Dobson and Elander 2009). For academics, these changes have 
meant the transition from tenure to contracted positions (Rinne and Jauhiainen 2012, 94). Scholars have thus been constantly pressured to prove their ability to attract external research funding and produce publications at a fast pace to consolidate university finances. As a result, universities have been transformed from intrinsically managed expert communities towards the direction of 'normal' workplace cultures, where basic research and teaching are increasingly under managerial control, surveillance and authority (Filander 2016, 12; see also Gonzales, Martinez and Ordu 2014).

It is crucial to scrutinise the human dimension of these managerialist reforms at a microlevel (Evans 2015). The invasion of managerialist practices in universities has many potential human and social costs, such as demotivation, decrease in creativity and loss of collegiality amongst university personnel (Czarniawska 2015, 38; GuzmanValenzuela and Di Napoli 2015; Jeanes, Loacker and Śliwa 2018). In this article we focus on academics representing educational sciences as they have been shown to hold critical attitudes towards universities' adoption of business practices. However, their stances towards managerialism were perceived almost as positive as those of academics in 'hard' sciences (Becher 1994) such as natural sciences and medicine. (Rinne et al 2012, 109-112.) The disciplinary culture of hard sciences can be regarded as competitive (Becher 1994) and thus more compatible with managerialism than the culture of educational sciences characterised by softer values, such as human growth. The relation between managerialism and educational sciences therefore needs more indepth examination, especially with the scarce international research on the topic.

Our analysis targets three units representing educational sciences in two Finnish universities where reforms in management structures and practices have occurred, and further reforms have been planned for the future. For our data, we use the responses to a 
work welfare survey conducted in the target units, focusing mainly on the open-ended responses. We investigate, what kinds of positionings towards the new management system, its principles and practices are constructed in the accounts of academics, and what kinds of ideals these positionings reflect. In the following sections, we discuss the basis of both traditional and new management systems in the Finnish university context, as well as present our data and methods, results and final conclusions.

\section{Traditional and new modes of university management}

Managerialism in universities can be regarded as a new mode of university governance based on autocratic control, striving for maximisation of effectiveness and outputs to gain financial profit. There is a clear contrast to the traditional mode of governance in universities, which uses control based on professional consensus and collegial decision making and strives for knowledge, research and truth. (Olssen 2002, 45; Kolsaker 2008.) Managerialism is extended by a complementary discourse, 'leaderism', which expresses leadership as a positive and inspiring phenomenon and promotes individual leaders as active change agents, who are able to define organisational issues and solutions and create shared values. Both managerialism and leaderism can be perceived as a set of beliefs framing and justifying changes in organisational and managerial practices. (O’Reilly and Reed 2010; Ekman, Lindgren and Packendorff 2017.) However, albeit manager's role is promoted in both leaderism and managerialism, they represent a somewhat different viewpoint on management and leadership; managerialism means controlling employee performance whereas leaderism implies creating a positive atmosphere in the work community. Leaderism represents an evolution of NPM and managerialism by striving for decreased bureaucracy in the organisation (O’Reilly and Reed 2011). 
Since managerialism rejects the primacy of professionals (Kolsaker 2008, 514), its logic differs substantially from that of professionalism. Generally, professionalism can be regarded as an organising principle for service-sector work, based on the knowledge, expertise and control of the work by the practitioners themselves, in contrast to hierarchical, bureaucratic and managerial control in organisations. Professional control is important because, due to the complexities of the work, only practitioners can understand its demands, processes, procedures and outcomes. (Freidson 2001; Evetts 2013.) Professionalism also includes a normative value system in work (Evetts 2013, 780). In the academic profession, disciplinary attachment is usually high; therefore, the profession is primarily fragmented rather than integrated by professionalism (Clark 1987, 381-382). However, academics across disciplines tend to share common moral and work values, such as commitment to the public good, altruistic concern for students, autonomy, educational expertise and pursuit of knowledge (Kolsaker 2008, 516; McInnis 2010, 149-150). Academic professionalism can thus be interpreted as control over academic work based on the autonomous expertise of academics, also involving shared academic values.

One of the traditional academic ideals is collegiality, which promotes academics' participation in the university's decision-making processes (Spiller 2010; Ylijoki and Ursin 2013). Collegiality is often associated with professionalism since both stress the practitioners' role in academic communities (Spiller 2010). While professionalism in universities is associated with academics' professional power and control over their own work, collegiality relates to their possibilities of influencing common issues in the university. However, since the university reforms in Finland, collegiality has lost its significance in decision making in universities. For instance, the university unit heads used to be collectively selected from the staff. However, since the 
inception of the New Universities Act, the unit managers have been chosen by the university board or another university organ, such as the university rector (Finnish Universities Act 2009).

Rinne and colleagues (2012) found in their study that Finnish university employees held generally fairly reserved attitudes towards the basic principles of the reforms. The academics opposed the universities' adoption of management practices from the private sector and regarded the present university policy as a threat to academic freedom. Furthermore, the majority of the respondents, representing 12 disciplines in two universities, thought that employees were unable to influence important matters in their universities. The respondent group that experienced the changes most positively comprised the administration's top managers (Rinne and Jauhiainen 2012, 98, 102), who could therefore be regarded as the winners in the universities' new power games.

However, there are various ways for academics to position themselves towards the managerialist changes in academia. Academics have shown bitterness towards the academic elite, opposed managerial pressures, expressed nostalgic yearning for the past, as well as complied to changes and supported them actively (Teelken 2012; Ylijoki 2014; Huang, Pang and Yu 2016). Academics have found ways to adapt to changing university values by retaining their own alternative value systems and professional identities (Clegg 2008; Kolsaker 2008). They have adjusted their actions to achieve their goals within the particular management system instead of being passive recipients of change (Kolsaker 2008; Nickson 2014). 


\section{Data and methods}

The research data consisted of responses to a work welfare survey where academics reacted to the recent changes in their work communities and their own work. By academics, we refer to professors, university lecturers, senior researchers, university instructors, and other university employees whose main duty is research and/or teaching. The survey was conducted in two Finnish universities (Cases 1 and 2) - in Case 1, in one larger unit (2014) and in Case 2, in two smaller units (2016). All three target units represented educational sciences, but the target units of Case 2 also included other related disciplines.

In Case 1, the survey questionnaire was sent to 103 employees, of whom 88 had research and/or teaching as their main duty, the remaining 15 persons included research assistants, coordinators and managers with no research or teaching duties. In Case 2, the questionnaire was sent to 93 employees, who all had teaching and/or research as their main duty. In Case 1, 78 individuals (76\%) responded; Case 2 had 38 respondents (41\%). The likely reasons for the higher response rate in Case 1 were the merger of smaller units into a larger whole that had escalated tensions in the work community and the high expectations for the survey to relieve the situation. In contrast, the lower response rate in Case 2 was partly caused by the organisation undergoing a transition process when the survey was conducted. Due to the higher response rate and the more plentiful and diverse open-ended responses in Case 1, our analysis focused on Case 1, and the data from Case 2 was used more to mirror our observations concerning Case 1. In both cases, the majority of the respondents were female (73\% in Case 1 and $68 \%$ in Case 2), the largest age group was over 55 years (44\% in Case 1 and $45 \%$ in Case 2), and the majority of the respondents held permanent positions (55\% in Case 1 and $68 \%$ in Case 2). 
In both case universities, large structural reforms had taken place in recent years. In Case 1, our study targeted a unit which was established in 2011 (nearly four years before we conducted the survey) by merging smaller units into one unit. Called a school, the unit was managed by a dean - a full-time manager. The unit combined personnel from earlier smaller units, comprising teacher-trainers from different subjects within educational sciences (e.g., early childhood, basic and vocational education), as well as research-oriented academics. Smaller groups called teams were later established inside the unit, they were managed by middle managers - academics who acted as the nearest superiors to the team members (i.e., their own colleagues).

In Case 2, the whole university was restructured in 2010, over five years before we conducted the survey. One large university was established by merging two geographically dispersed smaller universities. At the same time, the former department structure was dismantled, and the departments were replaced by units called schools that consisted of several disciplines. In Case 2, each of the target units of our study was managed by a professor with research and/or teaching as a part-time duty. She/he was the nearest superior to the academics working in the unit. Moreover, a decision had been made about a further merger to integrate one additional unit into a larger unit. The respondents from Case 2 included both teacher-trainers and research-oriented academics.

The welfare survey had a total of over 50 questions, where 34 were qualitative open-ended questions, and the rest were quantitative. In this article, we focus mainly on the responses to the qualitative questions, assuming that they indicate the respondents' social positioning towards the new management system more clearly than the responses to the quantitative, more structured questions. However, our analysis was supported by the quantitative data insofar as it was assumed to reflect the respondents' positionings 
towards the new management system. In the analysis, we used the responses to 26 openended questions that were related to different aspects of work and work welfare, such as working conditions and managerial issues.

In the analysis, we applied a narrative-discursive approach (Davies and Harré 1990). Individuals talk about their experiences by means of words, concepts and forms of speech provided by the social and discursive reality of the shared narrative environment of the target units (Gubrium and Holstein 2008). We examined how in their open-ended accounts, the survey respondents elaborated on their different social positionings towards the restructured management system (Davies and Harré 1990; Bamberg 2004). Individual accounts are multivoiced and diverse; thus, they also consist of multiple and somewhat contradictory positionings towards the new management system. We analysed the similarities and differences between the positionings, identified the vocabulary that manifested the positionings towards the new management system and counted some frequently used terms to figure out their relevance in our data.

In the analysis of the data, the respondents' open-ended accounts were organised under themes based on the positionings towards the new management system. Since many of the respondents positioned themselves differently in relation to various questions of the survey and thus related to more than one positioning, most of the accounts were divided into several themes. The accounts which did not adequately indicate the positioning of an individual were excluded from the analysis. Finally, the accounts of 56 respondents (54\% of the potential respondents) in Case 1 and 24 respondents (26\%) in Case 2, altogether 80 accounts, were included in the analysis. The main themes formed in the analysis representing different positionings towards the restructured management system comprised 1) resistance to managerialism, 2) desire for 
collective responsibility and collegiality, 3) desire for strong management and leadership and 4) emphasis on the individual.

\section{Positionings towards the restructured management system}

\section{Working conditions and shared aspirations framing the positionings}

The academics' positionings towards the restructured management system were assumed to reflect the respondents' general wellbeing at work, possibilities to influence common issues in their unit, goals that they strove for in their work and issues causing burdens to them. Therefore, the analysis was supported by the survey's quantitative questions addressing these issues, presented in this section.

The respondents' general wellbeing was indicated by their replies to the question 'What is your own wellbeing at work at the moment?' The average values were 3.4 in Case 1 and 3.9 in Case 2, using a 5-point Likert-scale, ranging from $1=$ 'very poor' to 5 $=$ 'very good'. The average value of Case 1 could reflect the strain the respondents talked about, for instance, too massive and unevenly distributed workloads and conflicts amongst members of the work community. In Case 2, the respondents' main concern was the forthcoming structural reform. The possibilities to influence common issues in the unit were considered quite low in both cases, with the average values of 2.6 in Case 1 and 2.7 in Case 2, manifesting the academics' weakened decision-making power at the grassroots level.

The most important goals in one's work were the same in both cases, as follows: 1) more profound expertise in one's own field, 2) doing the work well and 3) widening one's expertise/competence, implying the significance of the pursuit of knowledge and 
commitment as traditional academic ideals for these academics. Balancing between work tasks was causing the largest burden on the respondents in both cases, suggesting that the restructured management system had not succeeded in appropriately allocating the academics' work. As many as 44 per cent of the respondents in Case 1 experienced a decrease in their work quality due to time pressure, whereas in Case 2 the corresponding percentage was 21 . In conclusion, based on the quantitative data of the survey, the two cases had similarities in the academics' individual goals but differences in their experienced working conditions. These similarities and differences were mirrored in the positionings of the respondents towards the restructured management system based on the open-ended accounts in the survey. The positionings are elaborated in the next sections.

\section{'Authoritarian management and overruling' - resistance to managerialism}

Case 1 had many accounts opposing and resisting general ideals of managerialism and managerialist practices. The respondents criticised the competition, the highlighted role of administration and management, bureaucracy, management based on numerical indicators and goals set from outside the work community. These managerialist principles and practices were perceived as threatening the meaningfulness of academic work and not part of the academic culture.

The administration and the management stare at numbers and don't seem to understand the nature of the work of a creative professional organisation. (Case 1, No. 26: female, under 40 years, on contract)

As the preceding quote illustrates, the respondents resist the prevailing managerialist logic in universities where academic work is subjected to control mechanisms that conflict with academic values, such as creativity. These accounts relate to the idea of 
academic professionalism (Kolsaker 2008) whereby the power to define and control the academic work should be in the hands of the academics themselves instead of the management. The accounts also resonate with the criticism towards managerialism identified by Teelken (2012) which was often caused by implementing managerialism without a direct relationship to the primary processes or neglecting the specific nature of universities as professional, autonomous institutions.

In Case 1, some respondents expressed their critique about increased managerial control. They complained about 'too much management' and criticised excessive control and bureaucracy that restricted the agency of the individuals. The critique was mostly aimed at their nearest superiors, the middle managers.

More boundaries and orders from the management without any discussions. Authoritarian management and 'overruling'. (Case 1, No. 22: female, over 55 years old, permanent position)

Since there were many middle managers in Case 1, the critique expressed in these kinds of accounts could be aimed at individual management styles of some managers in the unit. However, it could also be interpreted more widely as criticism for too strict control mechanisms regulating academic work in general. This may reflect an experience of research and teaching being increasingly defined externally, diminishing academics' sense of professional ownership (Guzman-Valenzuela and Di Napoli 2015).

In Case 2, some respondents complained about the competition and the profitseeking mentality in the university. However, since the main critique targeted the lack of possibilities to exert influence in the university, these accounts were included in the positioning 'desire for collective responsibility and collegiality' discussed next. 


\section{'The voice of employees is left unheard' - desire for collective responsibility and collegiality}

Both Case 1 and Case 2 had many respondents who highlighted the importance of democracy, communality, the possibilities to be heard and to influence common issues, as well as equal rights and duties in the work community. Their accounts stressed collective responsibility for common issues instead of prioritising the management's role. These respondents criticised unevenly distributed workloads, undemocratic and unclear decision-making processes, as well as the hierarchy, and called for more power for the academics.

It feels like the decisions are made behind closed doors and the voice of the employees is left unheard. (Case 1, No. 51: female, under 40 years old, permanent position)

This citation exemplifies the criticism about managerialism where the decision-making power is in the hands of the management instead of the academics. These kinds of accounts relate to the wish for collegiality based on professionalism that is nonetheless lacking. These accounts mirror the Nordic welfare states' ideology prioritising democracy, participation and equality, which have been the cornerstones in the development of the education systems in these countries (Arnesen and Lundahl 2006) and could be viewed as shared professional ideals for academics in the field of education. The lack of academics' decision-making power became evident also in Rinne and colleagues' $(2012,181)$ study. Over $80 \%$ of the academics responding to their survey considered that important issues were decided above academic employees, and over $60 \%$ stated that their views expressed to the decision makers had no effect.

In Case 2, the critique was aimed mostly at the university level management instead of the unit level. The respondents in Case 2 were generally more interested in 
influencing the decisions made at the university and the faculty levels. Therefore, they criticised the academics' lack of decision-making power at the university and the manager-centredness of the decision-making system.

The current rector- and dean-centred management regulations should be dismantled and a new management system that supports democratic decision-making should be created. (Case 2, No. 15: gender not disclosed, 40-55 years old, permanent position)

This quote illustrates the conflict that many respondents in Case 2 observed between university democracy and the restructured management system in the university. They supported collegiality in their accounts and several also made suggestions about reforming the system.

\section{'The unit needs a strong leader' - desire for strong management and leadership}

In Case 1, many respondents regarded managers, especially the unit dean, as key agents in the work community. These positionings thus represented quite a different stance towards power relations in the work community compared with the positionings elaborated in the preceding sections. There was a demand for strong leadership, as well as expectations for the management to have visions and to develop the work community. These respondents expected the management to influence a wide range of issues, most importantly to enhance the communality and the wellbeing in the unit.

--- The dean should have a clear vision of how the work welfare is constructed and maintained. [...] The unit needs a strong leader, who has visions and opinions about what kind of community he is willing to develop. (Case 1, No. 35: gender not disclosed, 40-55 years, permanent position) 
This excerpt emphasises the central role expected from the management in the work community. These expectations resonate with leaderism where powerful, heroic leaders are perceived as change agents inspiring others in collaborative efforts. In Case 1, where the dean was a full-time manager, expectations for him were particularly strong. The dean, who had recently started in his position, was also expected to relieve the difficult situation in the work community. In leaderism, individual leaders are also seen as able to unify diverging interests between employees (Ekman, Lindgren and Packendorff 2017), which could also explain some of the high expectations for the dean in Case 1.

In Case 1, some respondents adhered to leaderism from a more individual perspective highlighting their own working conditions, such as individual support, positive feedback and encouragement from the management, rather than organisational issues. The management was expected to show appreciation for and interest in the work of individual academics. Since control exercised by the management was mainly construed as a necessary or unquestioned fact framing the work of the academics, these respondents complied with managerialist principles. The control was regarded as legitimate even if all the rules and managerialist practices were not always considered meaningful. In these positionings, the respondents regarded academic work, in many ways, just as any kind of work (Filander 2016, 12).

[I expect] [s]traightforward leadership, so that I'm able to know what's expected of me and what I should do. I don't want constant instructions on how to do my work, but I value openness so that I don't need to guess or rely on indirect channels to get information about my duties and priorities. (Case 1, No. 61: Female, over 55 years old, on contract)

The preceding quote illustrates agreement on control mechanisms, which is typical, especially for the employees in Case 1 without a permanent position. It relates to 
conforming to managerialist practices and performing them to preserve one's position in the academic community which could be viewed as crucial, especially for academics on temporary contracts (Archer 2008).

In Case 2, the management's role was generally not stressed. In their accounts, the respondents were also not prone to regard themselves as subordinates.

\section{'Hopefully teaching and researching according to one's own interests will be possible in the future, too'-emphasis on the individual}

There were also positionings, especially in Case 1, characterised by self-responsibility, individualism and autonomy in relation to one's work. Such a discourse is in line with Siivonen and Brunila's (2014) reference to the 'entrepreneurial discourse', which highlights autonomy, freedom and the self-responsibility for one's own success. In these positionings, individual possibilities were considered unlimited, and organisational structures, managerial practices and other issues framing academic work were not perceived as restricting individual choices. Consequently, individuals were also held responsible for organising their own work.

I feel that my own organising and prioritising skills are a bit insufficient.

Difficulties in coordinating my duties are mostly due to that (Case 1, No. 61: female, over 55 years old, on contract)

This citation illustrates a positioning where an individual is viewed as an active agent with possibilities to influence one's own work and personal working conditions. An individual is responsible for one's sense of belonging to the work community and for communality, information retrieval and one's own wellbeing at work by prioritising and adjusting one's own requirements. As a result, individual success or failure is construed 
in terms of entrepreneurial virtues or personal failings instead of systemic attributes (Davies and Petersen 2005; Harvey 2007, 66-67).

In Case 2, some respondents highlighted autonomy, independence and working alone. In these accounts, an individual was perceived as a central agent, but different from Case 1, an individual's possibilities to influence one's working conditions were not clearly emphasised. These positionings could be regarded as manifestations of academics' professional autonomy, referring to their freedom to teach and research without fear of intervention (Enders, De Boer and Weyer 2013).

I like the fact that the unit manager expresses trust in the researchers and allows them to work in peace. I don't feel that I am under too much control or observation. (Case 2, No. 38: female, under 40 years old, on contract)

These respondents in Case 2 regarded themselves as autonomous actors with no strong need to be managed. Instead, they expected the management to let them work in peace and to trust them as academics. There was no criticism towards the current management for any attempt to apply too much control over individual work. The respondents were quite satisfied with the current management, as long as it kept a distance. Lower expectations for the management could be at least partly due to the absence of full-time managers in the target units in Case 2.

In both cases, academic freedom and individual autonomy were generally important issues for the respondents. In the responses to the open-ended question 'What aspects of your work are the best?', in Case 1, independence and/or freedom at work was mentioned most often after students; 19 respondents (24\%) brought up independence and/or freedom as the best aspects of their work. In Case 2, this tendency 
was even stronger; independence and/or freedom was mentioned most often; 11 respondents (29\%) regarded either or both as best aspects of their work.

Hopefully, teaching and researching according to one's own interests, strengths and expertise will be possible in the future, too. [...] As long as these basic issues remain under one's own control, the academic work will remain meaningful. (Case 1, No. 78: male, 40-55 years old, permanent position)

As exemplified in the preceding excerpt and the cited percentages, in both cases, there is a tendency to regard oneself - despite the control exercised by the management - as quite an autonomous actor in relation to one's own work. However, since autonomy can be regarded as largely incompatible with managerialism (Shields and Watermeyer 2018), the quote could also imply that managerialist practices could reduce the academics' autonomy in the future. This kind of scenario would likely threaten the sense of meaningfulness of academic work.

In summary, Table 1 presents the four positionings elaborated in the preceding sections, indicating the vocabulary characteristic of the positionings in both cases.

[Table 1 near here]

\section{Discussion and conclusions}

The positionings traced in this study can be interpreted as different ways to respond to the pressures created by managerialist changes in universities. They take a stance on who should be in charge and have the power to define academic work, its goals and working conditions. In spite of their different views towards the management system, the positionings traced in this study were not distinct categories dividing academics in target units, since many respondents related to several positionings in their accounts. 
The balancing between positionings relates to a contradiction between professionalism and managerialism described by academics in other studies, as well; a tension between independence fostered by specialised knowledge and the necessity to comply to control and rules in the search for excellence (Teelken 2015; Carli, Tagliaventi and Cutolo 2018).

In the positioning 'desire for strong management and leadership' managerialist practices and/or highlighted role of the management were seen as unproblematic framings of academic work. Leaderism, as 'a softer side of managerialism' (see also O'Reilly and Reed 2010), may be a tempting discourse in a situation that needs a leader to maintain the coherence of a large heterogeneous unit and support the individual academics struggling with the pressures of efficiency and accountability. In contrast, the positionings 'resistance to managerialism' and 'desire for collective responsibility and collegiality' adhered to professionalism, advocating the power of the academics over their work instead of the managerial power. The positioning 'emphasis on the individual', in turn, could be seen as representing both entrepreneurial ideals compatible with managerialism (Nikunen 2012) and autonomy characteristic of professionalism (Kolsaker 2008). As Ylijoki (2013) points out, academic culture includes various layers which combine old and new elements and balance between continuity and change.

Along with NPM-driven university reforms, management systems in universities have been designed according to managerialist principles. However, as our data analysis implies, traditional professional ideals have not ceased to exist in the university context; collegiality, university democracy and academic freedom have remained important for academics, albeit the new management system is perceived as neglecting these ideals. This argument is in line with Clegg's (2008) notion that in spite of managerialist changes in universities, academics are not likely to abandon their own values despite 
being in conflict with managerialist ideals. As our target units represented educational sciences, unsurprisingly, the respondents would likely regard learning and gaining more expertise and competence as important goals in their work. Since learning takes time and requires immersing oneself in issues, it may be difficult to combine it with managerialist ideals, such as efficiency and competitiveness. In conclusion, albeit some academics expressed compliance with managerialism and manager-centredness, our study suggests that academics - specifically in educational sciences - who have experienced managerialist reforms in their work communities could be more prone to adhere to the ideals of professionalism and collegiality than those of managerialism.

In our study, we scrutinised two universities, Case 1 with one large heterogeneous unit managed by a full-time manager - the dean - and middle managers, and Case 2 with two smaller and more homogeneous units, with neither full-time managers nor middle managers. In Case 1, there were criticisms about too strict managerial control over the work of academics and excessive bureaucracy at the unit level, which is assumed to be related to more complex and more profoundly restructured management system of the large unit. This corresponds to Ylijoki's (2014) remark that structural reforms in academia are associated with increasing bureaucracy, which takes time away from the core activities.

The decrease in the work quality due to time pressure experienced by many respondents in Case 1 could be at least partly due to the increased administrative work related to the excessive managerial control exercised in Case 1, which might disturb the basic work of academics. Expectations of competitiveness and high performance, which were particularly strong in the large unit, may also cause excess workload and increased strain for academics. Moreover, the reforms in management system may also reduce the autonomy which is needed for academics to experience their work as meaningful. These 
findings suggest that managerial control applied to the work of the academics at the unit level - the university grassroots - will not increase the quality of teaching and research in practice. Consequently, too profound managerialist restructurings in the university may work against the original goals of the university reforms.

\section{References}

Aarrevaara, T., I. R. Dobson and C. Elander 2009. "Brave New World: Higher Education Reform in Finland." Higher Education Management and Policy 21 (2): $1-18$.

Archer, L. 2008. “The new neoliberal subjects?: Young/er academics' constructions of professional identity." Journal of Education Policy 23 (3): 385-403.

Arnesen, A-L. and L. Lundahl 2006. "Still Social and Democratic? Inclusive Education Policies in the Nordic Welfare States." Scandinavian Journal of Educational Research 50 (3): 285-300.

Bamberg, M. 2004. "Positioning with Davie Hogan. Stories, tellings, and identities.” In Narrative analysis: Studying the development of individuals in society, edited by C. Daiute and C. Lightfoot, 135-157. Thousand Oaks: Sage.

Becher, T. 1994. "The significance of disciplinary differences.” Studies in Higher Education 19 (2): 151-161. DOI: 10.1080/03075079412331382007.

Carli, G., M. R. Tagliaventi and D. Cutolo 2018. "One size does not fit all: the influence of individual and contextual factors on research excellence in academia." Studies in Higher Education, DOI: 10.1080/03075079.2018.1466873

Carvalho, T. and P. Videira 2017. "Losing autonomy? Restructuring higher education institutions governance and relations between teaching and non-teaching staff." Studies in Higher Education, DOI: 10.1080/03075079.2017.1401059

Clark, B. R. 1987. “Conclusions”. In The Academic Profession: National, Disciplinary and Institutional Settings, edited by B. R. Clark, 371-399. London: University of California Press.

Clegg, S. 2008. “Academic Identities under Threat?”. British Educational Journal 34 (3): 329-345. 
Chandler, J., J. Barry and H. Clarke 2002. "Stressing academe: The wear and tear of the New Public Management.” Human Relations 55 (9): 1051-1069.

Czarniawska, B. 2015. "University fashions: on ideas whose time has come.” In Universities in the flux of time: An exploration of time and temporality in university life, edited by P. Gibbs, O.-H. Ylijoki, C. Guzman-Valenzuela and R. Barnett, 32-45. Oxon \& New York: Routledge.

Davies, B. and R. Harré 1990. "Positioning: The Discursive Production of Selves." Journal for the Theory of Social Behavior 20 (1): 43-63.

Davies, B. and E. B. Petersen 2005. "Neo-liberal discourse in the Academy: The forestalling of (collective) resistance." Learning and Teaching in the Social Sciences 2 (2): 77-97.

Deem, R. and K. J. Brehony 2005. "Management as ideology: the case of 'new managerialism' in higher education." Oxford Review of Education (31) 2: 217235.

Degn, L. 2016. “Academic sensemaking and behavioural responses - exploring how academics perceive and respond to identity threats in times of turmoil." Studies in Higher Education. 1-17. DOI: 10.1080/03075079.2016.1168796.

De Vries, M. and J. Nemec 2013. "Public Sector Reform: An Overview of Recent Literature and Research on NPM and Alternative Paths." International Journal of Public Sector Management 26 (1): 4-16.

Enders, J., H. De Boer and E. Weyer 2013. "Regulatory autonomy and performance: The reform of higher education re-visited." Higher Education 65 (1): 5-23.

Ekman, M., M. Lindgren and J. Packendorff 2017. "Universities need leadership, academics need management: discursive tensions and voids in the deregulation of Swedish higher education legislation.” Higher Education. DOI 10.1007/s10734-017-0140-2.

Evetts, J. 2013. "Professionalism: Value and ideology." Current Sociology Review 61 (5-6): 778-796.

Evans, L. 2015. "The worst of times? A tale of two higher education institutions in France: their merger and its impact on staff working lives." Studies in Higher Education. 1-19. DOI: 10.1080/03075079.2015.1119107.

Filander, K. 2016. "Yliopistojen moraalijärjestys ja toimijuuden tilat - Miten rakentaa vaihtoehtoja vaihtoehdottomuuteen?" [Moral order of university and spaces for 
agency - How to create alternatives in the state of uniformity]. Tiedepolitiikka $41(2): 9-20$.

Finnish Ministry of Education and Culture 2017. "University reform.” Accessed January 252017.

http://www.minedu.fi/OPM/Koulutus/koulutuspolitiikka/Hankkeet/Yliopistolait oksen_uudistaminen/?lang=en

Finnish Universities Act 558/2009. Accessed February 142017.

http://www.finlex.fi/en/laki/kaannokset/2009/en20090558.pdf

Freidson, E. 2001. Professionalism: The Third Logic. London: Polity Press.

Gonzales, L. D., E. Martinez and C. Ordu 2014. "Exploring faculty experiences in a striving university through the lens of academic capitalism." Studies in Higher Education 39 (7): 1097-1115. DOI: 10.1080/03075079.2013.777401.

Gordon, G. and C. Whitchurch. 2010. Academic and Professional Identities in Higher Education: The Challenges of a Diversifying Workforce. Abingdon: Routledge.

Gubrium, J. and J. Holstein 2008. Narrative ethnography. In Handbook of emergent methods, edited by N. Hesse-Biber and P. Leavy, 241-264. New York: The Gilford Press.

Guzman-Valenzuela, C. and R. Di Napoli 2015. "Competing narratives of time in the managerial university: the contradictions of fast time and slow time." In Universities in the flux of time, edited by P. Gibbs, O.-H. Ylijoki, C. GuzmanValenzuela and R. Barnett, 154-167. Oxon \& New York: Routledge.

Harvey, D. 2007. A brief history of neoliberalism. New York: Oxford University Press.

Huang, Y., S. K. Pang, and S. Yu 2016. “Academic identities and university faculty responses to new managerialist reforms: experiences from China." Studies in Higher Education. 1-19. DOI: 10.1080/03075079.2016.1157860.

Jeanes, E., B. Loacker and M. Śliwa 2018. "Complexities, challenges and implications of collaborative work within a regime of performance measurement: the case of management and organisation studies." Studies in Higher Education, DOI: 10.1080/03075079.2018.1453793

Kolsaker, A. 2008. "Academic Professionalism in the managerialist era: a study of English Universities." Studies in Higher Education 33 (5): 513-525. DOI: 10.1080/03075070802372885. 
McInnis, C. 2010. "Traditions of academic professionalism and shifting academic identities." In Academic and professional identities in higher education, edited by G. Gordon and C. Whitchurch, 147-65. New York: Routledge.

Nickson, A. 2014. "A Qualitative Case Study Exploring the Nature of New Managerialism in UK Higher Education and Its Impact on Individual Academics' Experience of Doing Research.” Journal of Research Administration 45 (1): 47-80.

Nikunen, M. 2012. "Changing university work, freedom, flexibility and family.” Studies in Higher Education 37 (6): 713-729.

Nokkala T. and A. Bladh 2014. "Institutional Autonomy and Academic Freedom in the Nordic Context - Similarities and Differences.” Higher Education Policy 27: $1-21$.

Rinne, R. and A. Jauhiainen 2012. "In the shifting sands of policy - University academics' and employees' views and experiences of Finlands new higher education policy." In Higher education research in Finland. Emerging structures and contemporary issues, edited by S. Ahola and D.M. Hoffman, 89110. Jyväskylä: Finnish Institute for Educational Research.

Rinne, R., A. Jauhiainen, H. Simola, R. Lehto, A. Jauhiainen and A. Laiho 2012. Valta, uusi yliopistopolitiikka ja yliopistotyö Suomessa: Managerialistinen hallintapolitiikka yliopistolaisten kokemana. [Power, new university politics and academic work in Finland: Managerial policy experienced by the academics.]. Suomen kasvatustieteellinen seura.

Olssen, M. 2002. The neo-liberal appropriation of tertiary education policy in New Zealand: Accountability, research and academic freedom. State-of-the-Art Monograph no. 8. Wellington: Association for Research in Education.

O'Reilly, D. and M. Reed 2010. “ 'Leaderism': An evolution of managerialism in UK public service reform." Public Administration 88 (4): 960-978.

O'Reilly, D. and M. Reed 2011. "The Grit in the Oyster: Professionalism, Managerialism and Leaderism as Discourses of UK Public Services Modernization." Organization Studies 32 (8): 1079-1101.

Shepherd, S. 2017. "Managerialism: an ideal type.” Studies in Higher Education. 1-11. DOI: $10.1080 / 03075079.2017 .1281239$ 
Shields, R. and R. Watermeyer 2018. "Competing institutional logics in universities in the United Kingdom: schism in the church of reason." Studies in Higher Education, DOI: 10.1080/03075079.2018.1504910

Siivonen , P. and K. Brunila 2014. "The making of entrepreneurial subjectivity in adult education." Studies in Continuing Education 36 (2): 160-172.

Spiller, D. 2010. "Language and academic leadership: exploring and evaluating the narratives." Higher Education Research \& Development. 29 (6): 679- 692.

Teelken, C. 2012. "Compliance or pragmatism: how do academics deal with managerialism in higher education? A comparative study in three countries." Studies in Higher Education 37 (3): 271-290.

Teelken, C. 2015. "Hybridity, Coping Mechanisms, and Academic Performance Management: Comparing Three Countries.” Public Administration 93 (2): 307323.

Välimaa, J. 2012. “The relationship between Finnish higher education and higher education research." In Higher education research in Finland, edited by S. Ahola and D.M. Hoffman, 27-48. Jyväskylä: Finnish Institute for Educational Research.

Ylijoki, O.-H. 2013. "Boundary-work between work and life in the high-speed university." Studies in Higher Education 38 (2): 242-255.

Ylijoki, O.-H. 2014. "University Under Structural Reform: A Micro-Level Perspective." Minerva 52: 55-75.

Ylijoki, O.-H. and J. Ursin 2013. "The construction of academic identity in the changes of Finnish higher education." Studies in Higher Education 38 (8): 1135-1149. 


\begin{tabular}{|l|l|}
\hline Positioning & Vocabulary used \\
\hline Resistance to managerialism & $\begin{array}{l}\text { competition, pressure for effectiveness, } \\
\text { bureaucracy*, administration*, power*, } \\
\text { control*, rules*, management structures*, } \\
\text { management policies** }\end{array}$ \\
\hline $\begin{array}{l}\text { Desire for collective responsibility and } \\
\text { collegiality }\end{array}$ & $\begin{array}{l}\text { possibilities to influence, distribution of } \\
\text { workload, communality, democracy, equality, } \\
\text { decision making processes*, hierarchy* }\end{array}$ \\
\hline $\begin{array}{l}\text { Desire for strong management and } \\
\text { leadership }\end{array}$ & $\begin{array}{l}\text { development, leadership, strategy*, vision*, } \\
\text { management's intervention*, support*, } \\
\text { appreciation* }\end{array}$ \\
\hline Emphasis on the individual & $\begin{array}{l}\text { working alone, autonomy, being active*, } \\
\text { individual responsibility*, influencing one's } \\
\text { own work* }\end{array}$ \\
\hline
\end{tabular}

Table 1. Positionings traced in the analysis

*Only in Case 1; **only in Case 2 